\title{
A Novel Fluorescent Chemosensor Based on Exciplex Signaling Mechanism
}

\author{
Jia-Sheng Wu, Jian-Hua Zhou, Peng-Fei Wang, Xiao-Hong Zhang,* and Shi-Kang Wu* \\ Nano-Organic Photoelectronic Laboratory, Technical Institute of Physics and Chemistry, \\ Chinese Academy of Sciences, Beijing, 100101, P. R. China \\ Graduate School of Chinese Academy of Sciences, Beijing, China \\ Zhangxh8@yahoo.com; wusk@mail.ipc.ac.cn
}

\section{Supporting information}

Synthesis of compound 1 


\section{Experimental section}

\section{Instruments and reagents}

All fluorescence spectra in this work were recorded in Hitachi F-4500 fluorescence spectrometer respectively. The ${ }^{1} \mathrm{H}$ NMR spectra were recorded at $300 \mathrm{MHz}$, Varian Gemin-300. And Mass spectra were recorded on a Finnigan 4021C MS-spectrometer.

2-Hydroxy-1-naphthaldehyde was purchased from Aldrich and used as received. 4-Aminoantipyrine and 1-naphthol were analytical grade from Beijing chemical works and were recrystallized once before use. Acetonitrile was chromatographically pure reagent. All anionic compounds such as tetra-n-butyl ammonium salts of $\mathrm{F}^{-}, \mathrm{Cl}^{-}, \mathrm{Br}^{-}, \mathrm{I}^{-}$, $\mathrm{H}_{2} \mathrm{PO}_{4}^{-}, \mathrm{NO}_{3}^{-}, \mathrm{HSO}_{4}^{-}, \mathrm{AcO}^{-}$were from Aldrich and used as received.

\section{Synthesis of compound 1}

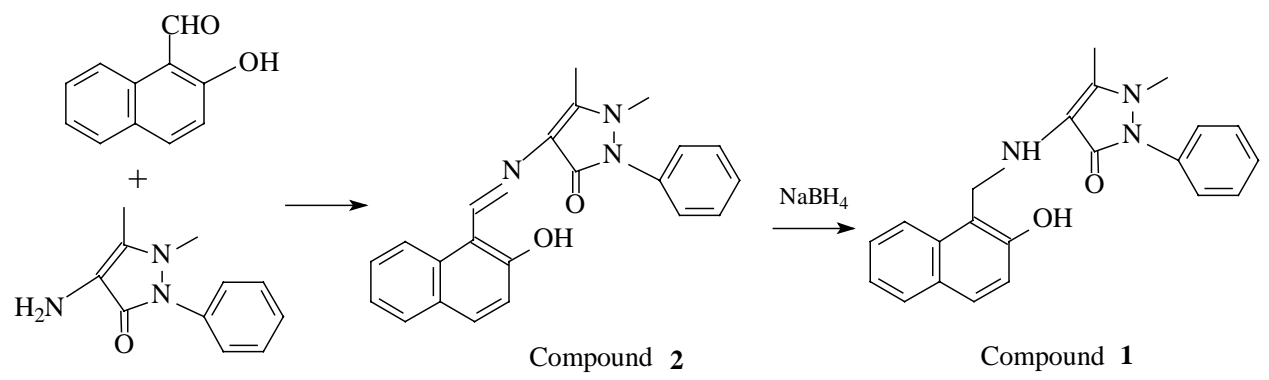

Scheme 3 Synthesis route of compound 1.

\section{Compound 2}

2-Hydroxy-1-naphthaldehyde (172 mg, $1 \mathrm{mmol}$ ) and 4-aminoantipyrine (202 mg, 1 mmol) were dissolved in $20 \mathrm{ml}$ absolute ethanol. The mixed solution was refluxed with stirring for $4 \mathrm{hrs}$, then evaporated to remove the solvent. The crude product was purified by column chromatography on a silica column eluted with petroleum 
ether/ethyl acetate, 1:1 by volume, and the yield of compound 2 (yellow powder) is $85 \%$.

${ }^{1} \mathrm{H}$ NMR $\left(300 \mathrm{MHz}, \mathrm{CDCl}_{3}\right) \delta 10.84(\mathrm{~s}, 1 \mathrm{H}, \mathrm{ArOH}, 8.24(\mathrm{~d}, 3 \mathrm{H}, \mathrm{ArH}), 7.82(\mathrm{~m}, 3 \mathrm{H}$ ArH), $7.47(\mathrm{~m}, 3 \mathrm{H}, \mathrm{ArH}), 7.22(\mathrm{~m}, 2 \mathrm{H}, \mathrm{ArH}), 3.66\left(\mathrm{~s}, 1 \mathrm{H}, \mathrm{ArCH}_{2}\right), 3.22(\mathrm{~s}, 3 \mathrm{H}$ $\left.\mathrm{C}=\mathrm{CCH}_{3}\right), 2.48\left(\mathrm{~s}, 3 \mathrm{H}, \mathrm{NCH}_{3}\right)$.

\section{Compound 1}

Compound 2 (100 mg) was dissolved in $20 \mathrm{ml}$ absolute ethanol. The solution was refluxed with stirring, then $1 \mathrm{~g} \mathrm{NaBH}_{4}$ was added gradually in several times. After addition of $\mathrm{NaBH}_{4}$ completely, the color of solution was changed from yellow to colorless. Continue to reflux for another $4 \mathrm{hrs,} \mathrm{then} \mathrm{the} \mathrm{solvent} \mathrm{was} \mathrm{evaporated,} \mathrm{the}$ crude product was obtained and further purified by chromatography on a silica column eluted with petroleum ether / ethyl acetate, 2/1 (by volume). The pure product of compound 1 (white powder) was obtained in $80 \%$ yield.

${ }^{1} \mathrm{H}$ NMR (300MHz, DMSO) $\delta 10.86$ (s, 1H, ArOH), 7.92 (d, 2H, ArH), 7.78 (d, 2H, ArH), 7.64 (d, 2H, ArH), 7.49 (m, 2H, ArH), 7.33 (m, 2H, ArH), 7.10 (m, 1H, ArH), $5.03(\mathrm{~s}, 1 \mathrm{H}, \mathrm{NH}), 3.52\left(\mathrm{~s}, 2 \mathrm{H}, \mathrm{ArCH}_{2}\right), 2.54\left(\mathrm{~m}, 3 \mathrm{H}, \mathrm{C}=\mathrm{CCH}_{3}\right), 2.13\left(\mathrm{~s}, 3 \mathrm{H}, \mathrm{NCH}_{3}\right)$. MS (m/e): $359(358,356,265,236,188,121,57)$.

Anal. Calcd for $\mathrm{C}_{22} \mathrm{H}_{21} \mathrm{~N}_{3} \mathrm{O}_{2}$ : C 73.52\%, H 5.89\%, N 11.69\%, O 8.90\%

Found: C 73.79\%, H 5.38\%, N $11.66 \%$, O $9.17 \%$ 